\title{
Análise empírica da fragilidade ambiental da bacia hidrográfica do rio Duas Bocas, Espírito Santo, Brasil
}

\section{Empirical Analysis of the environmental fragility of the Duas Bocas River basin, Espírito Santo, Brazil}

\author{
James Rafael Ulisses dos Santos ${ }^{1 *} \bowtie$ (iD), Eberval Marchioro ${ }^{2} \bowtie$ (iD) \\ 1Programa de Pós-Graduação em Geografia, Universidade Federal do Espírito Santo, Vitória, \\ Espírito Santo, Brasil \\ 2Programa de Pós-Graduação em Geografia, Universidade Federal do Espírito Santo, Vitória, \\ Espírito Santo, Brasil \\ E-mail: ebervalm@gmail.com \\ *E-mail para correspondência: jamesrulisses@gmail.com
}

Recebido (Received): 12/08/2019 Aceito (Accepted):29/05/2020

\begin{abstract}
Resumo: $\mathrm{O}$ estudo teve como propósito analisar a Fragilidade Ambiental Potencial $\left(\mathrm{F}_{\mathrm{AP}}\right)$ e Emergente $\left(\mathrm{F}_{\mathrm{AE}}\right)$ da bacia hidrográfica do rio Duas Bocas, Espírito Santo, por meio da integração das variáveis: declividade, geomorfologia, solos, uso e cobertura da terra e precipitação de 1970, 2008 e 2012. A metodologia dividiu-se em três etapas: a primeira correspondeu a pesquisas bibliográficas e aquisição de dados vetoriais e matriciais. $\mathrm{Na}$ segunda etapa foram realizados levantamentos de campo para o reconhecimento da área e validação dos produtos cartográficos in loco. A terceira etapa ficou a cargo dos trabalhos de gabinete com a elaboração dos produtos cartográficos. Com a análise dos resultados contatou-se que a $\mathrm{F}_{\mathrm{AP}}$ apresentou as classes alta e muito alta na nas porções central e superior da bacia, com presença de Cambissolos Háplicos e Neossolos Litólicos em relevo fortemente dissecado e declividades acima de 30\%. Na porção inferior as classes foram baixa e média com presença de Latossolos Vermelho-Amarelo e Gleissolos, em relevo suave ondulado e plano, com declividade entre 0 a $6 \%$ e $6 \%$ a $12 \%$. A $\mathrm{F}_{\mathrm{AE}}$ teve uma atenuação na porção superior, devido ao uso da terra (mata nativa), com classes muito baixa e baixa. Já na porção central a classe foi alta e média (exceção 1970), e na inferior classe baixa e média, tendo pastagem como uso e alguns pontos com classe muito baixa, devida a fragmentos de mata nativa, com alta e média em 1970 na planície fluvial. Contudo, a metodologia utilizada mostrou-se satisfatória quanto à fragilidade ambiental.
\end{abstract}

Palavras-Chave: Fragilidade Ambiental, Bacias Hidrográficas, SIG.

Abstract: The study aimed to analyze Potential Environmental Fragility $\left(F_{A P}\right)$ and Emergent $\left(F_{A E}\right)$ of the Duas Bocas river basin, Espírito Santo, through the integration of slope, soil, geomorphology, land use and land cover and precipitation from 1970, 2008 and 2012.The methodology was divided into three stages: the first corresponded to bibliographic research and acquisition of matrix and vector cartographic data. In the second stage, field surveys were carried out to recognize the area and validate cartographic products in loco. The third stage was in charge of the cabinet work with the elaboration of cartographic products. With the analysis of the results, it was found that the $F_{A P}$ presented the upper and very high classes in the central and upper portions of the basin, with the presence of Haplic Cambisols and Lithic Neossols in strongly dissected relief and slopes above 30\%. In the lower portion, the classes were low and medium with the presence of Red-Yellow Latosols and Gleysols, in smooth wavy and flat relief, with a slope between 0 to 6\% and $6 \%$ to $12 \%$. The $F_{A E}$ had an attenuation in the upper portion, due to land use (native forest), with very low and low class. In the central portion, the class was high and medium (exception 1970), and in the lower low and middle class, with pasture as use and some points with very low class, due to fragments of native forest, with high and medium in 1970 in the floodplain. However, the methodology used proved to be satisfactory in terms of environmental fragility.

Keywords: Environmental Fragility, River Basins, GIS. 


\section{Introdução}

O funcionamento dos ambientes naturais passa por constantes alterações devido às intervenções antrópicas que ocorrem numa velocidade maior do que aquela suportada pela natureza. Quando não planejadas, essas intervenções acarretam um conjunto de desequilíbrios funcionais e por isso trazem consequências à sobrevivência humana (SOUZA; VALE, 2016). As incursões do homem sobre o meio ambiente natural, por mais organizadas e planejadas que sejam, não criam e muito menos modificam as leis da natureza; apenas interferem nos fluxos de energia e matéria, alterando suas intensidades, forçando a natureza a buscar novos arranjos de equilíbrio funcional (ROSS, 2006; AMARAL; ROSS, 2009).

A intensa ocupação e as transformações dos ambientes naturais pelo ser humano, tem alterado as paisagens e seus aspectos naturais, sociais e culturais (RODRIGUEZ et al., 2007; JÚNIOR; OLIVEIRA, 2015). Cumpre esclarecer que paisagem não deve ser entendida apenas na ótica dos elementos da natureza, mas, como resultante da combinação dinâmica, portanto, instável, configurada por elementos físicos, biológicos e antrópicos (BERTRAND, 2007). A paisagem resulta da inter-relação dinâmica dos elementos naturais e humanos, e na medida em que a natureza é apreendida e manipulada pela ação do homem, constitui historicamente o reflexo dessa organização. A paisagem pode ser dividida em dois segmentos: o natural e o cultural. O natural refere-se à combinação de variáveis como geologia, geomorfologia, vegetação, solos e precipitação, enquanto que a cultural, humanizada, engloba todas as transformações protagonizadas pelo homem, nos ambientes sejam rurais e/ou urbanos (SILVEIRA, 2009; SCHIER, 2003; MAXIMIANO, 2004).

Os estudos da paisagem, a princípio, tiveram como enfoque a descrição das formas da superfície terrestre, sendo gradativamente e temporalmente introduzidas as alterações antrópicas sobre o meio ambiente. Nesse ínterim houve, contudo, a individualização das paisagens culturais frente às paisagens naturais, mas sem em nenhum momento perder as suas interligações mútuas. Por outro lado, a ação humana é vista como o principal vetor de transformações; ademais, reconhece-se que as paisagens efetivamente naturais são praticamente inexistentes (SALGUEIRO, 2001).

A fragilidade dos ambientes naturais associada as atividades humanas pode ser maior ou menor em razão dos seus aspectos genéticos. A propósito, em algumas regiões da Terra, os ambientes naturais comportam-se ou comportavam-se em estado de equilíbrio dinâmico até o momento em que o ser humano começou gradualmente a intervir de forma mais intensa na exploração dos recursos naturais (ROSS, 1994). Desse modo, a fragilidade ambiental se configura como a sensibilidade inerente aos ecossistemas frente as pressões ambientais, relacionadas também a diversas ameaças que tem a capacidade de alterar o equilíbrio de um sistema (RATCLIFFE, 1971).

A análise da fragilidade dos ambientes naturais e antropizados tem uma importância fundamental como ferramenta de gestão e ordenamento territorial. Em uma bacia hidrográfica, uma das maneiras mais eficientes de determinar a fragilidade ambiental é por meio da análise integrada, permitindo avaliar as potencialidades e suscetibilidades dos elementos da paisagem. Assim, as interações entre variáveis tornam-se indispensáveis para a tomada de decisão em uma bacia hidrográfica (JAIN; GOEL, 2002; CUNHA, 2008; CRUZ et al., 2010; CARMO et al., 2011; MARTÍN-DUQUE et al., 2012; ROSS, 2012; BOJÓRQUEZ-TAPIA et al., 2013; VALLE, 2016).

Uma bacia hidrográfica pode ser compreendida como uma unidade de planejamento e gestão, composta pelas unidades geoambientais, a saber: geologia, geomorfologia, pedologia, vegetação, hidroclimatológicas e socioeconômicas (CUNHA, 2008). Para Santos (2004), trata-se de um sistema natural bem delimitado espacialmente, constituído por um conjunto de terras topograficamente drenadas por um rio principal e seus afluentes, onde ocorre uma interação desses componentes, de maneira integrada.

Evidenciou-se, contudo, que ao longo das últimas décadas muitas transformações ocorreram devido aos avanços tecnológicos, sociais e econômicos, acarretando mudanças nos cenários ambientais, que, de certa forma, passou a contribuir de maneira determinante e significativa na modificação dos sistemas ambientais. $\mathrm{Na}$ conexão com os atributos naturais, as ações antrópicas têm possibilitado uma fragilidade de maior ou menor proporção, em detrimento dos seus aspectos genéticos (SPÖRL; ROSS, 2004).

Para tanto, as transformações que ocorrem nos diferentes componentes do meio físico/natural proporcionarão maiores prejuízos no funcionamento do sistema, alterando o seu estado de equilíbrio dinâmico. Esses elementos quando analisados e compreendidos de maneira integrada, auxiliam na elaboração de prognósticos e diagnósticos das várias categorias hierárquicas da fragilidade dos ambientes naturais (SPÖRL; ROSS, 2004). Nesse contexto, a pesquisa teve como objetivo, analisar a fragilidade ambiental da bacia hidrográfica do rio Duas Bocas por meio da integração entre elementos naturais e antrópicos que compõem a paisagem, com o propósito de auxiliar na gestão, planejamento e em tomadas de decisões. 


\subsection{Caracterização da área de estudo}

A área de estudo localiza-se entre os municípios de Santa Leopoldina, Cariacica e Viana, no Estado do Espírito Santo, Brasil, compreendida entre as coordenadas 7764921 e 7755681 S e 355302 e 339683 W. Possui uma extensão de $92,27 \mathrm{~km}^{2}$, da qual $18,71 \mathrm{~km}^{2}(20,28 \%)$ corresponde a Santa Leopoldina, $73,51 \mathrm{~km}^{2}$ $(79,67 \%)$ a Cariacica e $0,05 \mathrm{~km}^{2}(0,06 \%)$ a Viana. Trata-se de uma sub-bacia da bacia hidrográfica do rio Santa Maria da Vitória, sendo esta responsável por parte do abastecimento de água da Região Metropolitana da Grande Vitória (RMGV) (Figura 1). Os principais córregos que formam a bacia do rio Duas Bocas são: Pau Amarelo, Naia-Assú, Panelas e Sertão Velho, que têm suas nascentes dentro da Reserva Biológica de Duas Bocas (REBIO de Duas Bocas). Outros córregos também compõem a bacia, como o do Sabão, Cachoeirinha, Porto do Engenho, da Manteiga, Taquaruçu, Andorinha, Retiro, Pau-Oco, Freio do Burro e Batinga (MARCHIORO; BARROSO, 1996; PERRONE, 1995; SANTOS; MARCHIORO, 2018).

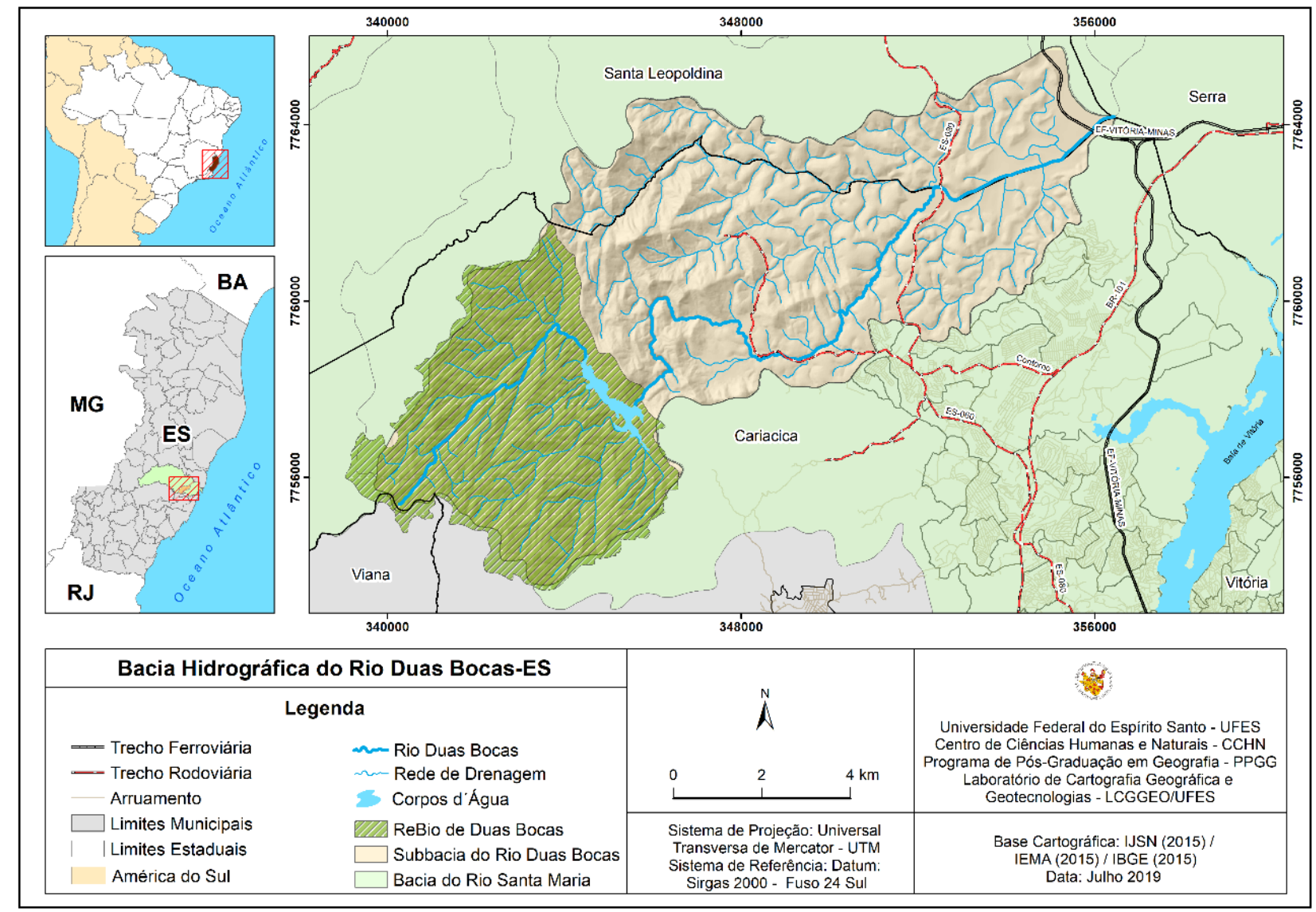

Figura 1: Localização da Bacia Hidrográfica do Rio Duas Bocas entre os municípios de Santa Leopoldina e Cariacica, Espírito Santo, Brasil.

A área de estudo está inserida entre as unidades geológicas: Complexo Novo Venécia, Maciço Granítico Vitória, Grupo Barreiras e Depósitos Fluviolagunares (CPRM, 2012). As unidades geomorfológicas correspondem aos Patamares Escalonados do Sul Capixaba, Colinas e Maciços Costeiros, Tabuleiros Costeiros e Planícies Fluviolagunares (RADAMBRASIL, 1983, IJSN, 2012). A cobertura pedológica, por sua vez, tem como classe: Cambissolos Háplicos, Gleissolos, Latossolos Vermelho-Amarelo, Latossolos Vermelho-Amarelo em associação com os Argissolos e Neossolos Litólicos (EMBRAPA, 2013).

Segundo Bastos et al. (2015), a precipitação das médias mensais da série histórica de 1983 a 2013 (Normal Climatológica) na área de estudo, apresentou o mês de dezembro como o mais chuvoso, com média de 222,60 mm, já o mês menos chuvoso foi junho, com média de 50,90 mm. A somatória dos totais pluviométricos acumulados dos meses mais chuvosos (novembro, dezembro e janeiro), correspondeu a $605,90 \mathrm{~mm}$ e os meses com os menores valores acumulados (junho, julho e agosto), apresentaram 171,00 mm (Figura 2). 


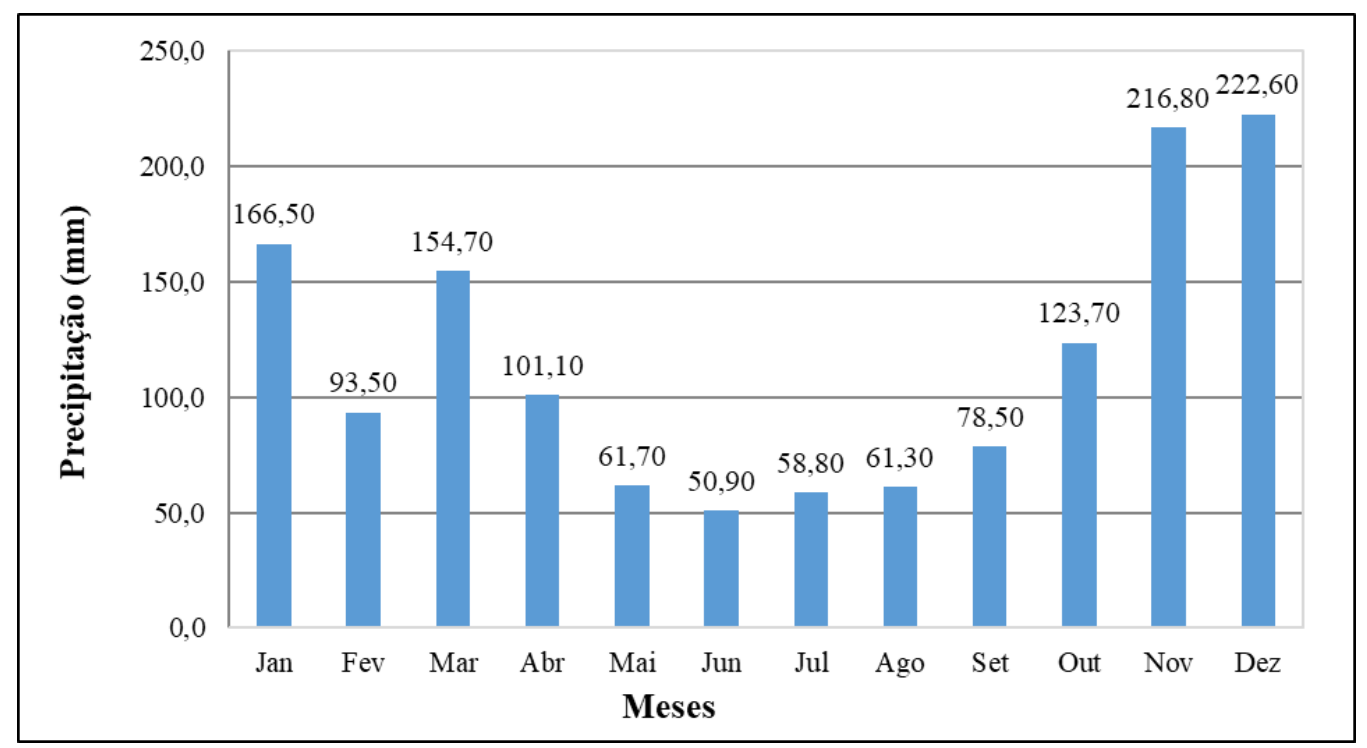

Figura 2: Distribuição média mensal de chuva da normal climatológica (1983-2013), da bacia hidrográfica do rio Duas Bocas (ES). Fonte: Bastos et al. (2015).

\section{Materiais e métodos}

Para alcançar os objetivos propostos, o estudo foi dividido em três etapas: na primeira foram realizadas as pesquisas bibliográficas, principalmente em periódicos científicos, sobre a temática e aquisição de dados cartográficos, em formato vetorial e matricial. A segunda etapa correspondeu aos levantamentos de campo, com o propósito de verificar in loco as características e atributos físicos e antrópicos da área de estudo.

Nos levantamentos de campo foram capturadas fotografias para criação de um acervo iconográfico e coletados pontos de coordenadas, com auxílio do Sistema de Navegação Global por Satélite (Global Navigation Satellite System - GNSS) com o equipamento eTrex 10 Garmin, disponibilizado pelo Laboratório de Cartografia Geográfica e Geotecnologias - LCGGEO/UFES e o GPS Essentials disponível para aparelhos de telefone móvel (com sistema operacional Android).

A terceira etapa consistiu na elaboração dos mapas e na modelagem para determinar a fragilidade ambiental com base na proposta de Ross (1994) e Gouveia e Ross (2019). Com a aplicação dessa metodologia pode-se ressaltar a importância de analisar de forma integrada, os elementos da paisagem, sendo utilizadas para esse estudo as seguintes variáveis: declividade, geomorfologia, solos, uso e cobertura da terra e precipitação. Todos os produtos para o cálculo da fragilidade ambiental foram convertidos do formato vetorial para raster (com resolução espacial de pixel de 10m), na escala de 1:70.000, no Sistema de Projeção Universal Transversa de Mercator - UTM, com o Datum SIRGAS 2000 e Zona 24 S. O software utilizado foi o ArcGIS $10.5^{T M}$, com licença concedida para o LCGGEO/UFES.

\subsection{Declividade}

Para elaboração da declividade, antes foram interpoladas as curvas de nível com equidistâncias de $5 \mathrm{~m} x$ $5 \mathrm{~m}$ na ferramenta Topo To Raster gerando assim um dado raster (Modelo Digital de Terreno - MDT), sendo posteriormente gerada a declividade na função Slope, e em seguida reclassificada no Reclassify, conforme a classificação proposta por Ross (1994), ficando o mapa na escala cartográfica de 1:70.000. Na (Tabela 1) são apresentados os graus de fragilidade com os intervalos de declividade propostos pelo supracitado autor. As curvas de nível de $5 \mathrm{~m}$ x 5m no formato vetorial foram adquiridas no Instituto Estadual do Meio Ambiente e dos Recursos Hídricos (IEMA). Podendo ser também adquiridas junto ao Instituto Capixaba de Pesquisa, Assistência Técnica e Extensão Rural (INCAPER) por meio do Sistema Integrado de Bases Geoespaciais do Estado do Espirito Santo (GEOBASES). 
Tabela 1: Categorias hierárquicas da fragilidade para a declividade. Adaptado de Ross (1994).

\begin{tabular}{cc}
\hline Categoria Hierárquica da Fragilidade & Declividade (\%) \\
\hline Muito Fraca -1 & até $6 \%$ \\
Fraca - 2 & 6 a $12 \%$ \\
Média - 3 & 12 a $20 \%$ \\
Forte - 4 & 20 a $30 \%$ \\
Muito Forte - 5 & Acima de 30 \\
\hline
\end{tabular}

\subsection{Geomorfologia}

A variável geomorfologia foi classificada a partir da base vetorial do Mapeamento Geomorfológico do Estado do Espírito Santo (IJSN, 2012), sendo esta uma atualização do projeto RADAMBRASIL (1983). Tratando-se de uma variável importante, pois demonstra como as feições geomorfológicas podem dá maior consistência aos resultados da fragilidade potencial e emergente como ressalta Gouveia e Ross (2019). Para a área de estudo, as seguintes unidades geomorfológicas são evidenciadas: Patamares Escalonados do Sul Capixaba, Colinas e Maciços Costeiros, Tabuleiros Costeiros e Planícies Fluviolagunares.

\subsection{Solos}

Os dados de solos em formato vetorial na escala de 1:5.000.000 foram adquiridos do levantamento da Empresa Brasileira de Pesquisa Agropecuária - EMBRAPA, do ano de 1979 e, reclassificado conforme (EMBRAPA, 2013), onde o mapa final ficou na escala de 1:70.000. A área de estudo é representada pelas seguintes classes: Cambissolos Háplicos, Gleissolos, Latossolos Vermelho-Amarelo, Latossolos VermelhoAmarelo/Argissolos e Neossolos Litólicos. Quanto ou grau de fragilidade as classes tiveram como base Ross (1994), conforme a (Tabela 2).

Tabela 2: Classes de solos quanto a fragilidade Ambiental. Fonte: Adaptado de Ross (1994).

\begin{tabular}{ccc}
\hline $\begin{array}{c}\text { Classes de } \\
\text { Fragilidade }\end{array}$ & Classes de Solos & Textura \\
\hline Muito Fraca - 1 & Latossolo Roxo, Latossolo Vermelho Escuro e Vermelho-amarelo & Argilosa \\
Fraca - 2 & Latossolo Amarelo e Vermelho Amarelo & Média/Argilosa \\
Média - 3 & Latossolo Vermelho-amarelo, Terra Roxa, Terra Bruna, Podzólico & Média/Argilosa \\
Forte - 4 & (Argissolo) Vermelho-amarelo e Gleissolo & Média/Arenosa \\
Muito Forte - 5 & Podzólico (Argissololo com cascalho, Litólicos (Neossolo Litólico) e Areias & - \\
\hline
\end{tabular}

\subsection{Uso e cobertura da terra}

A classificação do uso e cobertura da terra de 1970 foi realizada a partir das fotografias aéreas do mesmo ano, disponibilizadas pelo Instituto de Defesa Agropecuária e Florestal do Estado do Espírito Santo (IDAF), na escala de 1:25.000. E ficando o mapa final de uso da terra na escala de 1:70.000. Já o uso da terra de 2008 foi classificado com base nas ortofotos de 2007/2008 cedidas pelo Instituto Estadual do Meio Ambiente e dos Recursos Hídricos (IEMA), na escala de 1:15:000 com resolução espacial de 1m, e o produto final ficou na escala de 1:70.000. O uso e cobertura da terra de 2012 foi classificado baseado nas ortofotos de 2012/2015, disponibilizadas também pelo Instituto Estadual do Meio Ambiente e dos Recursos Hídricos (IEMA), na escala de 1:10.000 com resolução espacial de $0,25 \mathrm{~m}$, e com o produto final na escala cartográfica de 1:70.000.

O uso e cobertura da terra teve como forma de classificação a manual ou em tela, que trata-se do processo de vetorização sobre a imagem ou ortofoto (sendo ideal que a imagem tenha uma boa resolução espacial, para que o produto final tenha precisão satisfatória) e sendo validados em campo. Para a classificação das tipologias e padrões de cores das classes do uso e cobertura da terra dos anos supracitados, teve-se como base o manual de Uso da Terra do Instituto Brasileiro de Geografia e Estatística (IBGE) de 2006. Já com relação aos graus de proteção dos tipos de uso da terra (Tabela 3) seguiu-se a determinação de Ross (1994). 
Tabela 3: Graus de proteção quanto ao tipo de cobertura vegetal. Fonte: Adaptado de Ross (1994).

\begin{tabular}{|c|c|}
\hline $\begin{array}{l}\text { Graus de } \\
\text { Proteção }\end{array}$ & Tipos de Cobertura Vegetal/Uso e Cobertura da Terra \\
\hline 1 & Florestas/matas naturais, florestas cultivadas com biodiversidade. \\
\hline 2 & $\begin{array}{c}\text { Formações arbustivas naturais com estratos herbáceo denso, formações arbustivas densa (mata } \\
\text { secundária, Cerrado Denso, Capoeira Densa), Mata Homogênea de Pinus densa, Pastagens cultivadas } \\
\text { com baixo pisoteio de gado, cultivo de ciclo longo como o cacau. }\end{array}$ \\
\hline 3 & $\begin{array}{l}\text { Cultivo de ciclo longo em curvas de nível/terraceamento como café, laranja com forrageiras entre ruas, } \\
\text { pastagens com baixo pisoteio, silvicultura de eucaliptos com sub-bosque de nativas. }\end{array}$ \\
\hline 4 & $\begin{array}{l}\text { Culturas de ciclo longo de baixa densidade (café, pimenta do reino, laranja com solo exposto entre } \\
\text { ruas), cultura de ciclo curto, arroz, trigo, feijão, soja, milho, algodão com cultivo em curvas de } \\
\text { nível/terraceamento. }\end{array}$ \\
\hline 5 & $\begin{array}{l}\text { Áreas desmatadas e queimadas recentemente, solo exposto por arado/gradeação, solo exposto ao longo } \\
\text { de caminhos e estradas, terraplenagem, culturas de ciclo curto sem práticas conservacionistas. }\end{array}$ \\
\hline
\end{tabular}

\subsection{Precipitação}

Os dados de precipitação utilizados neste trabalho foram disponibilizados pela Agência Nacional de Águas (ANA) e pelo Instituto Capixaba de Pesquisa, Assistência Técnica e Extensão Rural (IMCAPER), do Estado do Espírito Santo, referentes às 13 estações meteorológicas distribuídas nas seguintes localidades: Viana, Vitória, Cariacica (Estação da Reserva Biológica de Duas Bocas), Fazenda Serra, Santa Teresa, Santa Maria de Jetibá (incluindo a estação da Serra do Garrafão e da Cachoeira Suíça), Santa Leopoldina e Marechal Floriano.

Para entrar no cálculo da fragilidade os dados de precipitação (Normal Climatológica - 1983 a 2013) foram interpolados utilizando o interpolador Spline, onde a espacialização apresentou intervalos de $1.307 \mathrm{~mm}$ a $1.377 \mathrm{~mm}, 1.377 \mathrm{~mm}$ a $1.447 \mathrm{~mm} ; 1.447 \mathrm{~mm}$ a $1.517 \mathrm{~mm}, 1.517 \mathrm{~mm}$ a $1.587 \mathrm{~mm}, 1.587 \mathrm{~mm}$ a $1.657 \mathrm{~mm}$. Contudo, o interpolador Spline trata-se de um método que une uma superfície de curvatura mínima por intermédio de dados pontuais de entrada, sendo mais adequado para áreas que representam tendências gradativas. Dessa forma, o método utiliza funções matemáticas e estatísticas que minimizam a curvatura da superfície terrestre, alcançando como resultado uma distribuição igualitária, conforme a altitude do local (AMORIM et al., 2008; CHILDS, 2004; ESRI, 2016; BASTOS et al., 2015). O erro quadrático médio apresentado pelo Spline foi de $445,5 \mathrm{~mm} /$ ano.

\subsection{Procedimento operacional para a análise da fragilidade ambiental}

Para a determinação da fragilidade dos ambientes naturais e antropizados conforme Ross (1994) e Gouveia e Ross (2019) baseado em Tricart (1977), realizou-se o cálculo da Fragilidade Ambiental Potencial $\left(\mathrm{F}_{\mathrm{AP}}\right)$ tendo como primeiro passo a soma das variáveis naturais, que nesse caso foram: declividade, geomorfologia, solos e precipitação e divide-se por 4. Já para a Fragilidade Ambiental Emergente $\left(\mathrm{F}_{\mathrm{AE}}\right)$ somou-se a $\mathrm{F}_{\mathrm{AP}}$ mais a variável uso e cobertura de terra e divide-se por 2 . Desse modo, através do método de Combinação Linear Ponderada (CLP) (Figura 3) foram estabelecidos os produtos finais da $\mathrm{F}_{\mathrm{AP}}$ e $\mathrm{F}_{\mathrm{AE}}$ com as seguintes classes: Muito Baixa, Baixa, Média, Alta e Muito Alta, sendo realizado em ambiente SIG, utilizando o software ArcGis ${ }^{T M} 10.1$ (ESRI, 2012), na extensão ArcMap $\rightarrow$ ArcTollbox $\rightarrow$ Spatial Analyst Tools $\rightarrow$ Map Álgebra $\rightarrow$ Raster Calculator. O cálculo da $\mathrm{F}_{\mathrm{AP}}$ é representado pela seguinte equação:

$$
\mathrm{F}_{\mathrm{AP}}=(\mathrm{D}+\mathrm{G}+\mathrm{S}+\mathrm{P}) / 4
$$

Onde: $\mathrm{F}_{\mathrm{AP}}=$ Fragilidade Ambiental Potencial; $\mathrm{D}=$ Declividade; $\mathrm{G}=$ Geomorfologia; $\mathrm{S}=$ Solos; $\mathrm{P}=$ Precipitação

Para o cálculo da $\mathrm{F}_{\mathrm{AE}}$, segue-se a somatória algébrica $\left(\sum \mathrm{F}\right)$, conforme a equação:

$$
\mathbf{F}_{\mathrm{AE}}=\left(\mathbf{F}_{\mathrm{AP}}+\mathrm{UCT}\right) / 2
$$

Onde: $\mathrm{F}_{\mathrm{AE}}=$ Fragilidade Ambiental Emergente; $\mathrm{F}_{\mathrm{AP}}=$ Fragilidade Ambiental Potencial; UCT = Uso e Cobertura da Terra 


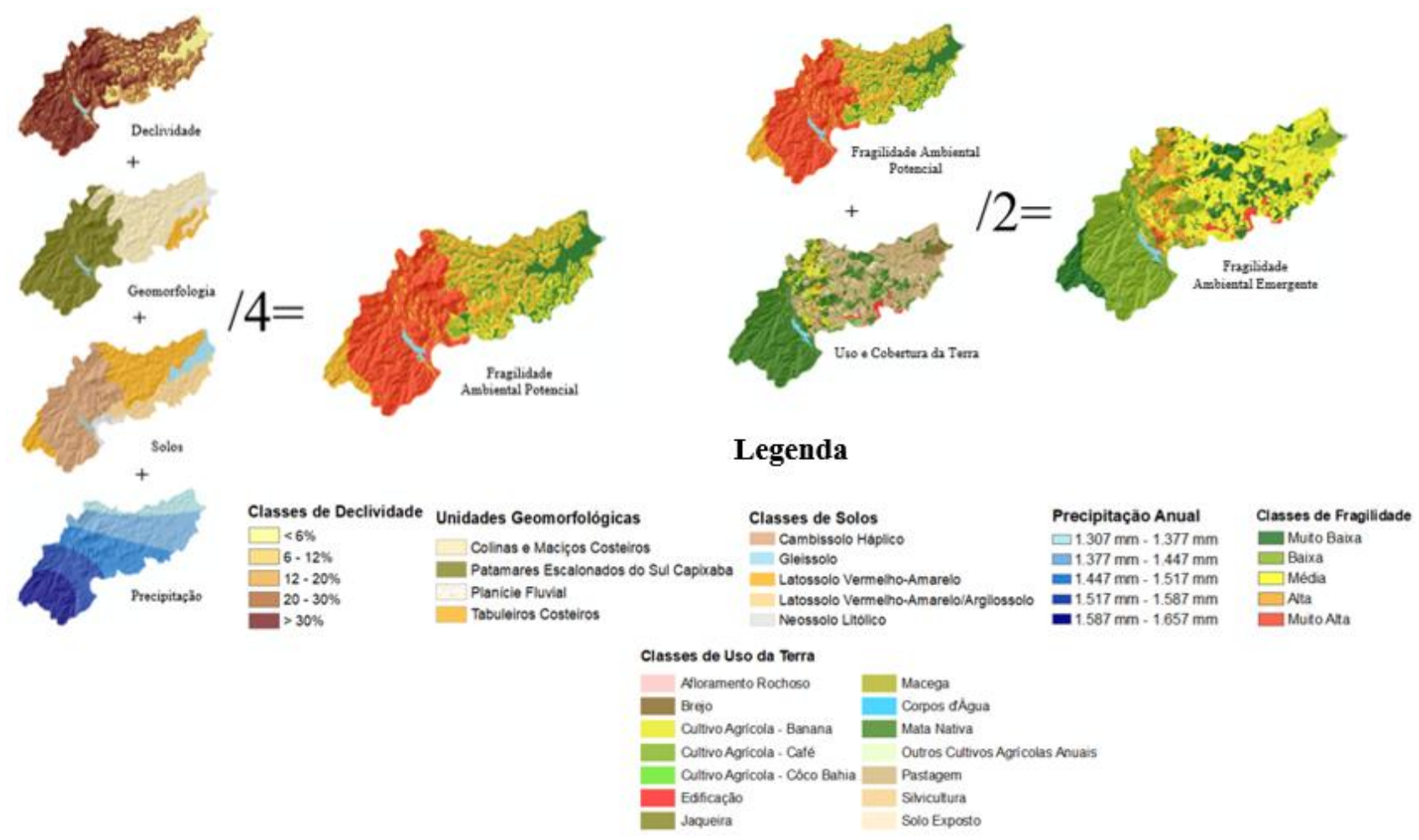

Figura 3: Representação das camadas para o cálculo da fragilidade dos ambientes naturais e antropizados. Fonte: Elaborado pelos autores (2019).

\section{Resultados e discussões}

De acordo com Santos (2017), a forma como o homem ocupa e utiliza o solo reflete sua relação com o meio ambiente, podendo revelar-se de forma danosa. Isso ocorre porque a exploração dos recursos naturais pelos interesses socioeconômicos pode ser utilizada de maneira irracional, comprometendo, pois, a manutenção dos ambientes naturais. O levantamento do uso e cobertura da terra tem grande importância devido aos efeitos do uso desordenado, que causam deterioração do ambiente e que pode vir a se constituir em uma problemática socioambiental.

Conforme pode ser visto na (Tabela 4) no ano de 1970 predominava na área de estudo, a classe de mata nativa, com 34,11\%, associada à vegetação de Mata Atlântica inserida nas encostas íngremes nos limites da então Reserva Florestal de Duas Bocas. Além dessa classe, é possível observar outras classes, como a de macega com $24,10 \%$, pastagem com $22,99 \%$, e o cultivo agrícola de banana com $9,01 \%$. Cumpre destacar que, no ano de 1965, com a criação da Reserva Florestal de Duas Bocas por meio da lei Estadual no 2.095 (sendo transformada em Reserva Biológica por meio da Lei Estadual $n^{\circ} 4.503$, de 02 de janeiro de 1991) (GOVERNO DO ESTADO DO ESPÍRITO SANTO, 2020), teve início as primeiras medidas de conservação e controle do avanço de certos tipos de cultivos, a exemplo dos cultivos agrícolas de banana e café e de pastagem sobre áreas de mata nativa e entorno da reserva. A distribuição espacial das classes de uso e cobertura da terra de 1970 pode ser melhor visualizada na (Figura 4a), com ênfase para as classes de mata nativa, macega, pastagem e cultivo agrícola de banana.

No ano de 2008 foram observadas como principais classes de uso e cobertura da terra predominantes a mata nativa, com $48,03 \%$, pastagem, com $31,87 \%$, e cultivo agrícola de banana, com $6,72 \%$. Já no ano de 2012 verificou-se o predomínio de mata nativa, com 48,27\%, tendo um aumento de $14,16 \%$ em relação a 1970 , e de $0,24 \%$ no comparativo com 2008. Essa classe aumentou devido à sua regeneração em relação às classes de macega $(24,10 \%, 1970 ; 2,94 \%, 2008$ e 2,19\%, 2012). A classe de pastagem também teve um aumento saindo de 22,99\% (1970), 31,87 (2008) e 31,51 (2012), representando a segunda maior, presente nas porções central e inferior da bacia. 
Tabela 4: Área e percentual do uso e cobertura da terra da bacia hidrográfica do rio Duas Bocas (ES). Fonte: Elaborado pelos Autores (2019).

\begin{tabular}{|c|c|c|c|c|c|c|c|c|c|}
\hline \multirow[b]{2}{*}{$\begin{array}{c}\text { Classes de Uso e } \\
\text { Cobertura da } \\
\text { Terra }\end{array}$} & \multicolumn{2}{|c|}{1970} & \multicolumn{2}{|c|}{2008} & \multicolumn{2}{|c|}{2012} & \multirow{2}{*}{$\begin{array}{c}\text { Perdas e } \\
\text { Ganhos } \\
(\%) 1970 \\
\text { a } 2008\end{array}$} & \multirow{2}{*}{$\begin{array}{c}\text { Perdas e } \\
\text { Ganhos } \\
(\%) 1970 \\
\text { a } 2012\end{array}$} & \multirow{2}{*}{$\begin{array}{c}\text { Perdas e } \\
\text { Ganhos } \\
\text { (\%) } 2008 \\
\text { a } 2012\end{array}$} \\
\hline & $\begin{array}{l}\text { Área } \\
\mathrm{km}^{2}\end{array}$ & $(\%)$ & $\begin{array}{l}\text { Área } \\
\mathrm{km}^{2}\end{array}$ & $(\%)$ & $\begin{array}{l}\text { Área } \\
\mathrm{km}^{2}\end{array}$ & $(\%)$ & & & \\
\hline $\begin{array}{l}\text { Afloramento } \\
\text { Rochoso }\end{array}$ & 0,56 & 0,62 & 1,25 & 1,35 & 1,15 & 1,25 & $+0,70 \%$ & $+0,63 \%$ & $-0,10 \%$ \\
\hline Brejo & 3,8 & 4,12 & 2,25 & 2,44 & 2,11 & 2,29 & $-1,68 \%$ & $-1,83 \%$ & $-0,15 \%$ \\
\hline $\begin{array}{c}\text { Cultivo Agrícola } \\
\text { de Banana }\end{array}$ & 8,31 & 9,01 & 6,20 & 6,72 & 6,25 & 6,78 & $-2,29 \%$ & $-2,23 \%$ & $+0,06 \%$ \\
\hline $\begin{array}{c}\text { Cultivo Agrícola de } \\
\text { Café }\end{array}$ & - & - & 1,12 & 1,22 & 1,66 & 1,80 & - & - & $+0,58 \%$ \\
\hline $\begin{array}{c}\text { Cultivo Agrícola de } \\
\text { Coco - da - Baía }\end{array}$ & - & - & 0,23 & 0,25 & 0,26 & 0,28 & - & - & $+0,03 \%$ \\
\hline Edificação & 1,06 & 1,14 & 1,44 & 1,56 & 2,15 & 2,33 & $+0,42 \%$ & $+1,19 \%$ & $+0,77 \%$ \\
\hline Jaqueira & - & - & 0,14 & 0,15 & 0,14 & 0,15 & - & - & $\mathbf{0 , 0 0}$ \\
\hline Macega & 22,24 & 24,10 & 2,71 & 2,94 & 2,02 & 2,19 & $-21,16 \%$ & $-21,91 \%$ & $-0,75 \%$ \\
\hline Corpos d’Água & 0,67 & 0,73 & 0,7 & 0,76 & 0,67 & 0,73 & $+0,03 \%$ & 0,00 & $-0,03 \%$ \\
\hline Mata Nativa & 31,48 & 34,11 & 44,32 & 48,03 & 44,54 & 48,27 & $+13,92 \%$ & $+14,16 \%$ & $+0,24 \%$ \\
\hline $\begin{array}{l}\text { Outros Cultivos } \\
\text { Agrícolas Anuais }\end{array}$ & - & - & 1,55 & 1,68 & 1,37 & 1,48 & - & - & $-0,20 \%$ \\
\hline Pastagem & 21,22 & 22,99 & 29,41 & 31,87 & 29,08 & 31,51 & $+\mathbf{8 , 8 8 \%}$ & $+8,52 \%$ & $-0,36 \%$ \\
\hline Silvicultura & - & - & 0,22 & 0,24 & 0,51 & 0,55 & - & - & $+0,31 \%$ \\
\hline Solo Exposto & 2,93 & 3,18 & 0,73 & 0,79 & 0,36 & 0,39 & $-2,39 \%$ & $-2,79$ & $-0,40 \%$ \\
\hline Total & 92,27 & 100 & 92,27 & 100 & 92,27 & 100 & & & \\
\hline
\end{tabular}

A classe de cultivo agrícola de banana está presente nas vertentes íngremes da porção central da bacia (Figuras 4 b e c). Concentra-se principalmente em relevo forte ondulado, montanhoso e escarpado com declividades e altitudes bastante expressivas, e cuja unidade geomorfológica corresponde aos Patamares Escalonados do Sul Capixaba. Esse cultivo apresentou percentuais distintos para os anos analisados: em 1970 era de $9,01 \%$; em 2008 de 6,72\%; e em 2012, 6,78\%, caracterizando, assim, uma redução respectivamente de $2,29 \%, 2,23 \%$ (1970 a 2008 e de 1970 a 2012), e um leve aumento de $0,06 \%$ (2008 a 2012).

Para a classe de edificação, foi observado um crescimento pouco expressivo dentro da bacia em relação a outras classes, onde em 1970 representava 1,14\%, passando para 1,56\% em 2008; e 2,33\% em 2012, que corresponde a um aumento respectivamente de 0,42\%, 1,19\% e 0,77\%. Esse aumento está atrelado principalmente ao processo de expansão urbana do município de Cariacica, que se encontra, em parte, dentro dos limites da bacia. No entanto, devido à presença da Rebio de Duas Bocas, que por se tratar de uma reserva biológica, abarca restrições quanto ao avanço das edificações.

$\mathrm{Na}$ (Figura 5a) é possível verificar parte da planície de inundação no baixo curso do rio Duas Bocas, inserida em relevo plano e suave ondulado com as menores declividades, e com presença de Gleissolos, que trata-se de uma classe com constante ou periódica saturação por água, além da forte gleização, devido ao ambiente redutor, teoricamente livre de oxigênio dissolvido, em função da saturação por água o ano inteiro, ou durante um período de longa duração, associado também ao consumo de oxigênio pela atividade biológica (EMBRAPA, 2013). A (Figura 5b) representa uma paisagem típica de propriedade rural com pecuária extensiva, cuja finalidade destina-se à pecuária de corte e/ou leiteira, estando inserida em relevo suave ondulado com a presença dos Latossolos Vermelho-Amarelo associados aos Argissolos. 


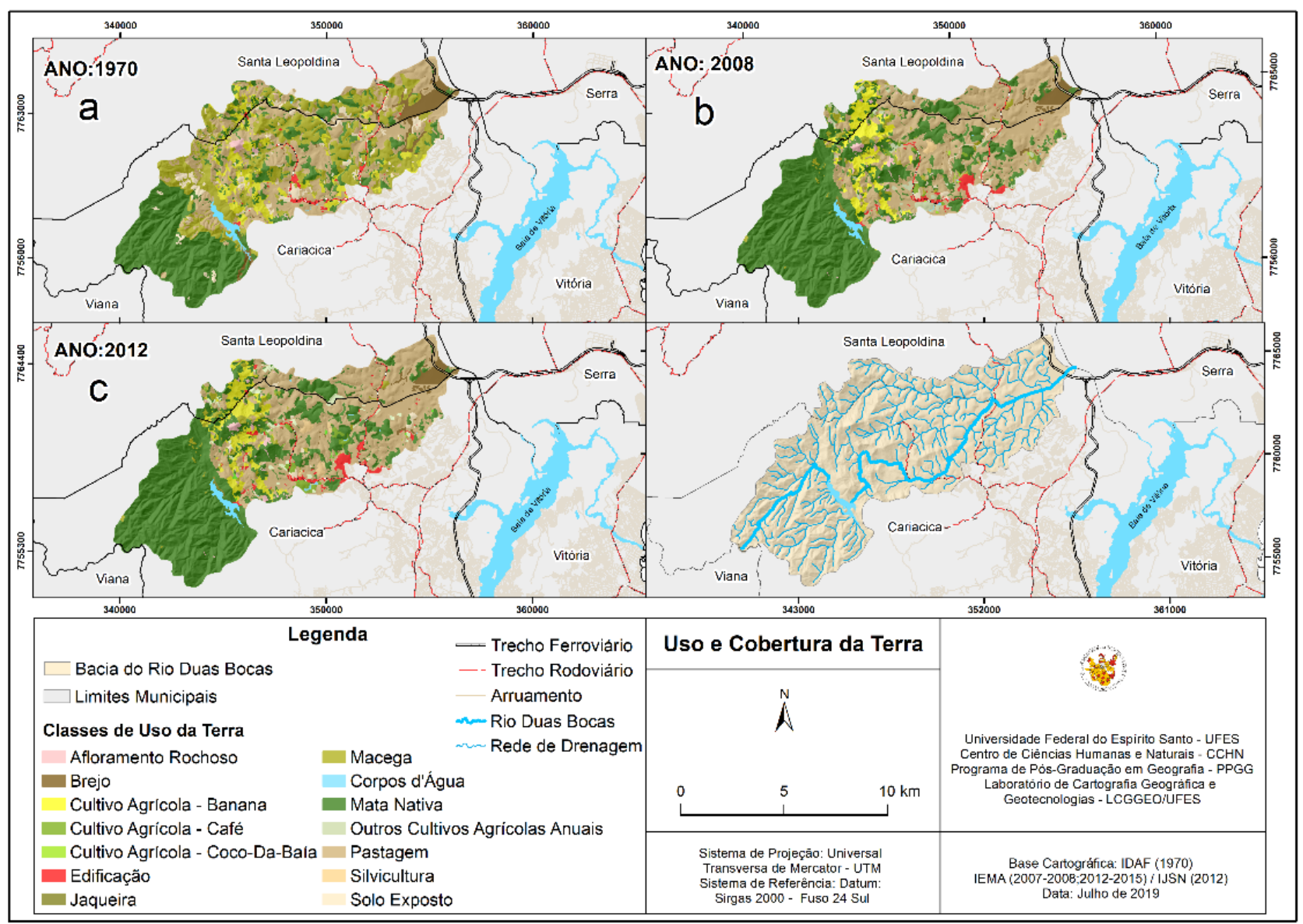

Figura 4: Uso e cobertura da terra da bacia hidrográfica do rio Duas Bocas (ES).

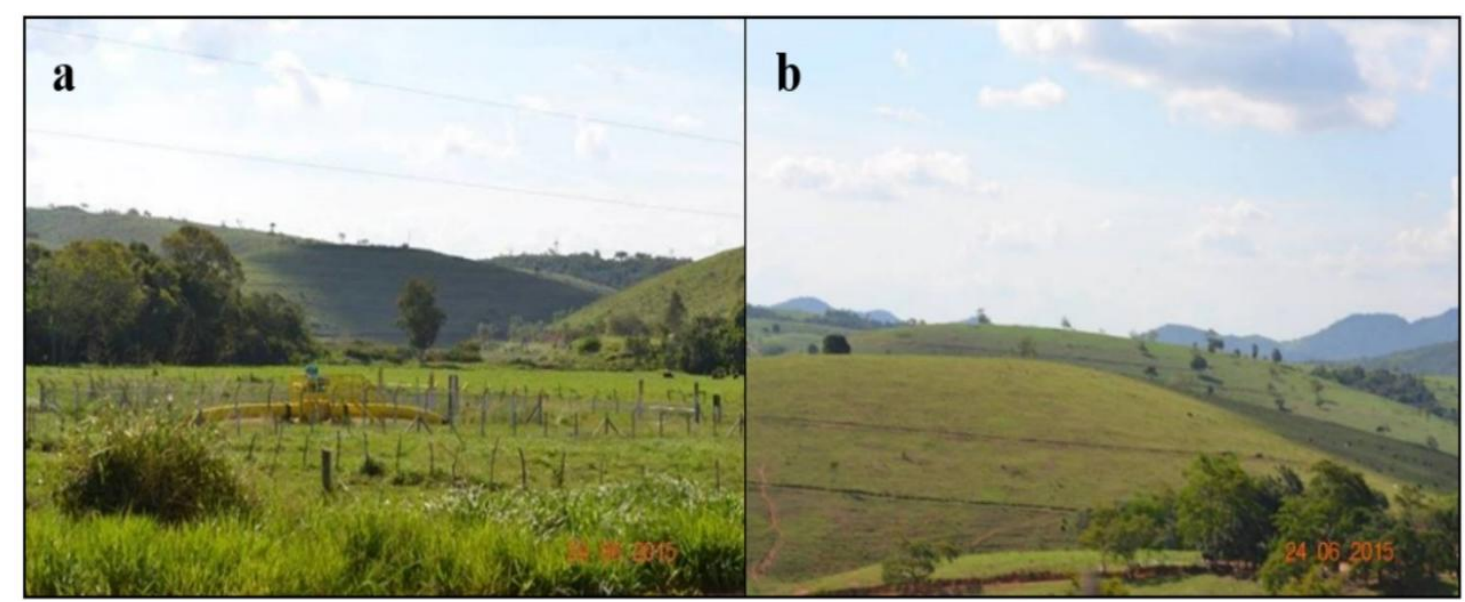

Figuras 5a: Planície de inundação com presença de pastagem em Gleissolos. 5b: Vertente com pastagem em Latossolos Vermelho-Amarelo associado aos Argissolos, sendo classes de solos pouco suscetíveis aos processos erosivos.

A (Figura 6a) apresenta uma vertente com cultivo agrícola de banana no seu terço inferior e médio e no superior (topo) com presença de mata nativa, tratando-se, portanto, de uma Área de Preservação Permanente (APP) de topo de morro. O relevo dessa porção é montanhoso e escarpado, com declividades superiores a 30\% e com predomínio de Cambissolo Háplico, sendo uma classe de solo suscetível aos processos erosivos. Por outro lado, na (Figura 6b) observa-se uma propriedade rural com pastagem e surgimento de processos erosivos pouco desenvolvidos, formando caminhos diferenciais, originados pelo pisoteio do gado, evidenciando pequenos sulcos (ravinas), em Latossolos Vermelho-Amarelo, e com relevo ondulado e forte ondulado. 


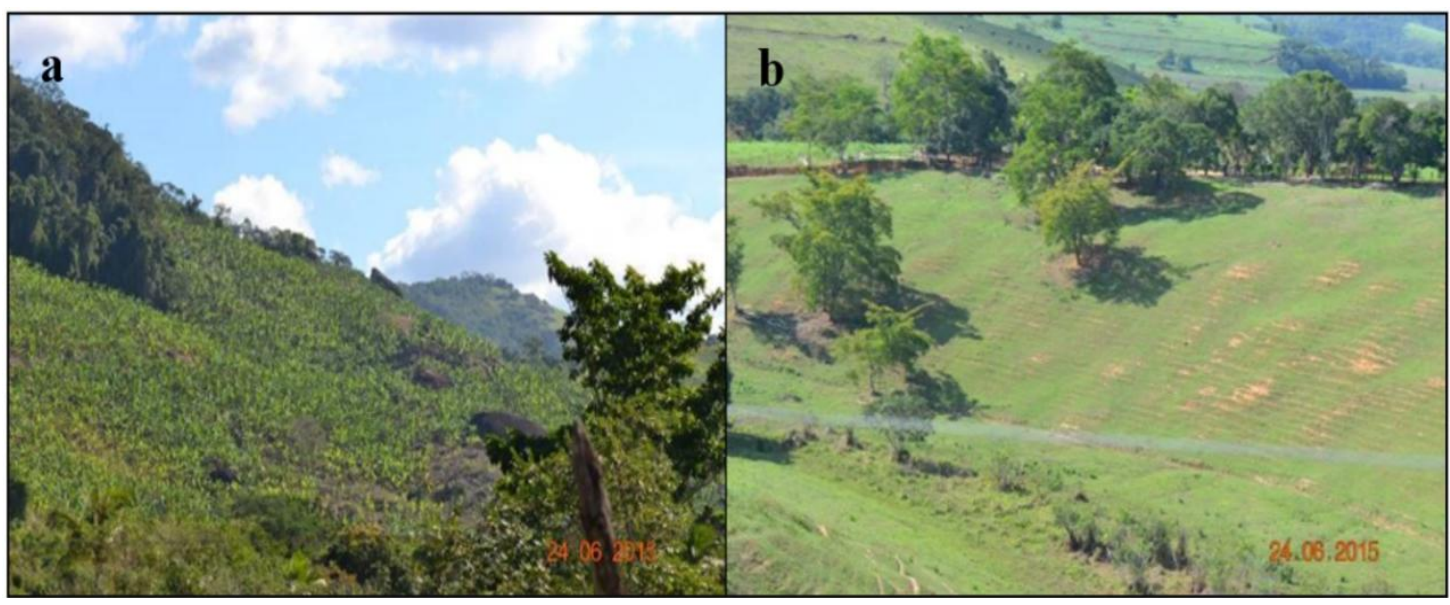

Figuras 6a: Vertente com forte presença de cultivo agrícola de banana em Cambissolos Háplicos, caracterizando-se uma $\mathrm{F}_{\mathrm{AE}}$ alta e muito alta. 6b: Fundo de vale em uma propriedade rural com cobertura de pastagem e espaçada vegetação arbórea, tendo como classe de solos os Latossolos Vermelho-Amarelo.

$\mathrm{Na}$ (Figura 7) são identificadas diferentes configurações na paisagem da área de estudo, onde pode ser observada uma vertente com presença de mata nativa do lado esquerdo, configurando-se assim, como uma porção conservada sem a ação direta do homem. E, do lado direito, verifica-se pastagem com marcas de pisoteio do gado, que resume a ação antrópica agindo diretamente nas transformações da paisagem. O relevo, nesse segmento, apresenta-se como forte ondulado, ondulado e plano (na planície de inundação), tendo como classe de solo na vertente que contrasta mata nativa com pastagem, Latossolos Vermelho-Amarelo, e na planície de inundação, a classe de Gleissolos.

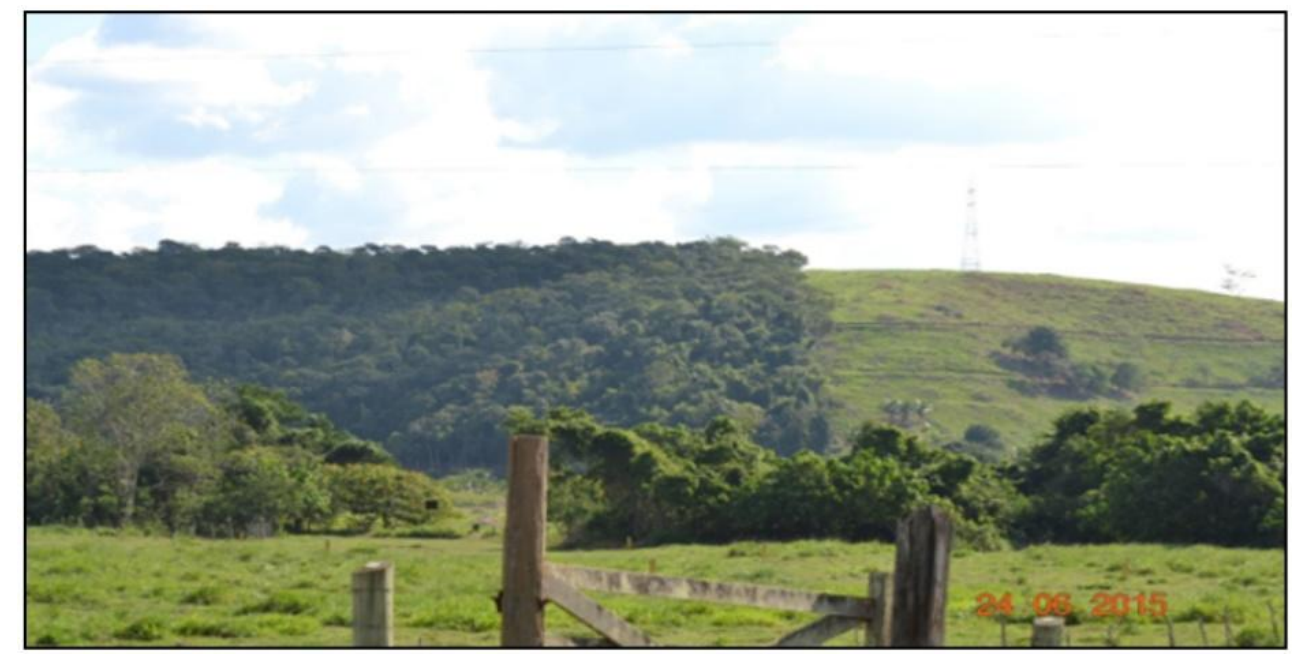

Figura 7: Vista de uma vertente que apresenta um contraste na paisagem, onde de um lado tem-se a ocupação por mata nativa e do outro lado pastagem

\subsection{Fragilidade ambiental potencial}

A determinação espacial da Fragilidade Ambiental Potencial $\left(\mathrm{F}_{\mathrm{AP}}\right)$ da bacia do rio Duas Bocas pode indicar o equilíbrio dinâmico natural sem a intervenção humana, que nesse caso, quando a classe de fragilidade é muito baixa e baixa, predominam os processos pedogenéticos, já quando as classes são alta e muito alta predominam os processos morfogenéticos. Silveira e Oka-Fiori (2007), estudando a bacia do rio Cubatãozinho no Estado do Paraná, demostraram que a fragilidade potencial ocorre nas poções com as maiores declividades, principalmente acima de $30 \%$, onde os aspectos geomorfológicos correlacionados ao substrato geológico e litológico com grande resistência, formam solos rasos, como os Cambissolos e os Nessolos Litólicos. Além de fatores como precipitações elevadas associadas a chuvas orográficas, tornando as vertentes instáveis propícias a movimentos de massa ou erosão.

$\mathrm{Na}$ área de estudo a $\mathrm{F}_{\mathrm{AP}}$ baixa e média foi observada na porção inferior, principalmente na planície de inundação do rio Duas Bocas para os processos erosivos, mas segundo Gouveia e Ross (2019) as áreas de 
planícies de inundação se configuram como de fragilidade alta e muito alta devido à instabilidade dos terrenos aos riscos de inundações. Nesse caso para os ricos de inundação nessa porção da bacia, a $\mathrm{F}_{\mathrm{AP}}$ foi média e alta. $\mathrm{O}$ relevo nesse setor é pouco dissecado (suave ondulado e plano), com declividade de 0 a $6 \%$ (plano) e 6 a 12\% (suave ondulado). Os solos correspondentes a essa porção têm como classes os Latossolos Vermelho-Amarelos e Gleissolos, que de acordo com Messias et al. (2012), em estudo realizado na sub-bacia hidrográfica do Rio Grande em Minas Gerais, sob influência da hidrelétrica de Funil, constataram que a $\mathrm{F}_{\mathrm{AP}}$ baixa estava associada a baixa suscetibilidade dos Latossolos Vermelho-Amarelo em declividade pouco acentuada com relevo plano e suave ondulado. No entanto, conforme Rocha et al. (2013) e Martins et al. (2018), a ocorrência da classe de $\mathrm{F}_{\mathrm{AP}}$ muito alta tem forte relação com as declividades acentuadas e a solos suscetíveis aos processos erosivos.

$\mathrm{Na}$ bacia do rio Duas Bocas as classes de $\mathrm{F}_{\mathrm{AP}}$ alta e muito alta para os anos analisados predominaram nas porções central e superior, principalmente, devido a forte dissecação do relevo (montanhoso e escarpado) com declividades maiores que 30\% atreladas a solos pouco desenvolvidos e suscetíveis aos processos erosivos como os Cambissolos Háplicos e Neossolos Litólicos. De acordo com Santos e Sobreira (2008), a forte dissecação do relevo associada a solos rasos tende a apresentar fragilidade alta, sendo agravada com precipitações elevadas.

Ressalta-se que essas classes de solos são propícias a erosão, principalmente quando da presença de precipitações com potencial erosivo, tendo em vista, que esse processo contribui para a remoção das camadas superficiais de solo (processo de lixiviação), impedindo, assim, a regeneração da vegetação e estabilidade das vertentes. Além disso, solos com textura arenosa, baixo teor de argila, pobre em matéria orgânica e pouca capacidade de reter água, são mais suscetíveis a erosão devido a elevada permeabilidade e tendo um alto grau de fragilidade (CASTRO et al.; 2011; CUNHA; BACANI, 2016; NETO; FERNANDES, 2015; MARTINS et al.; 2018).

Contudo, para a área de estudo o mapa da $\mathrm{F}_{\mathrm{AP}}$ dos anos de 1970, 2008 e 2012 (Figura 8a), apresentou o mesmo resultado devido as variáveis declividade, geomorfologia, solos e precipitação terem sido as mesmas, sendo possível observar que para $\mathrm{F}_{\mathrm{AP}}$ na porção inferior predominaram as classes muito baixa, baixa e média (sendo média e alta na planície para os riscos de inundações), em função da cobertura pedológica dos Latossolos Vermelho-Amarelos associados aos Argissolos e os Gleissolos, nas menores declividades e em relevo pouco dissecado. Já para as porções central e superior as classes de maior representatividade foram a alta e muito alta, com exceção para um pequeno setor superior que teve classe média devido a presença de Latossolo Vermelho-Amarelo (pouco suscetível a erosão) e declividade menos acentuada (relevo menos dissecado).

\subsection{Fragilidade ambiental emergente}

A determinação da $\mathrm{F}_{\mathrm{AE}}$ leva em consideração o estágio de equilíbrio da paisagem em relação às atividades antrópicas, sendo resultado da combinação da $\mathrm{F}_{\mathrm{AP}}$ mais a variável $\mathrm{F}_{\mathrm{UCT}}$. Conforme Silveira e Oka-Fiori (2007), para a bacia rio Cubatãozinho, foi constatado que a classes intermediária de fragilidade emergente, ou seja, a média, teve relação direta com as porções onde os resultados da fragilidade potencial indicavam classes com instabilidade alta e muito alta, porém sendo atenuadas devido a presença de cobertura vegetal preservada ou com mínimas mudanças em relação as práticas antrópicas. As áreas que evidenciam um equilíbrio de $\mathrm{F}_{\mathrm{AE}}$ intermediário integrado aos parâmetros naturais e ao uso da terra (incluindo a cobertura vegetal) passa a amenizar a atuação de processos erosivos, movimentos de massa e inundações. Contudo, alterações no uso da terra podem dinamizar mudanças no estado de equilíbrio, provocando aumento dos processos físicos, e com a supressão da cobertura vegetal leva a uma nova caracterização da $\mathrm{F}_{\mathrm{AE}}$ (SILVEIRA; OKA-FIORI, 2007).

Valle et al. (2016) estudando a fragilidade ambiental na bacia do rio Aldeia Velha no Estado do Rio de Janeiro, destacaram que as áreas da bacia que sofreram perdas consideráveis de cobertura vegetal causaram instabilidade nas classes de solos, o que acabou acarretando em uma $\mathrm{F}_{\mathrm{AE}}$ alta e muito alta. Isso caracteriza-se como resultado das práticas de manejo incorretas em relevo (de elevada dissecação e declividade) com potencial de suscetibilidade aos processos erosivos. Por outro lado, a cobertura florestal fornece maior proteção ao solo, contribuindo para maior capacidade de infiltração de água e a diminuição do escoamento superficial (surface runoff). Além de garantir uma manutenção das relações ecológicas, estabelecendo um ponto de equilíbrio ambiental, e assim auxiliando na redução da suscetibilidade a erosão dos solos e a inundação nas planícies fluviais (KAWAKUBO et al., 2005; VALLE et al.; 2016).

Para a área de estudo a $\mathrm{F}_{\mathrm{AP}}$, que é resultante da integração das variáveis físicas, foi bastante atenuada em relação a $\mathrm{F}_{\mathrm{AE}}$, isso deve-se principalmente a adição do uso e cobertura da terra como pode ser observado nos 
mapas de 1970, 2008 e 2012 (Figuras 8 b, c e d). Nas porções superior e central da bacia a $F_{A P}$ apresentou classes alta e muito alta correspondendo as vertentes com declividades acima de $30 \%$ em relevo com forte dissecação e tendo como principais classes de solos os Cambissolos Háplicos e Neossolos Litólicos, pouco desenvolvidos e muito suscetíveis aos processos erosivos. Já a $\mathrm{F}_{\mathrm{AE}}$ na porção superior da área tanto para $\mathrm{o}$ ano de 2008 como 2012 apresentou classes baixa e muito baixa, com exceção para o ano de 1970 que também foram observadas as classes média e alta. Essa mudança aconteceu em decorrência do uso da terra para esse setor correspondendo a mata nativa, que desse modo, passou a atenuar a $\mathrm{F}_{\mathrm{AP}}$ tornando os solos menos suscetíveis a erosão.

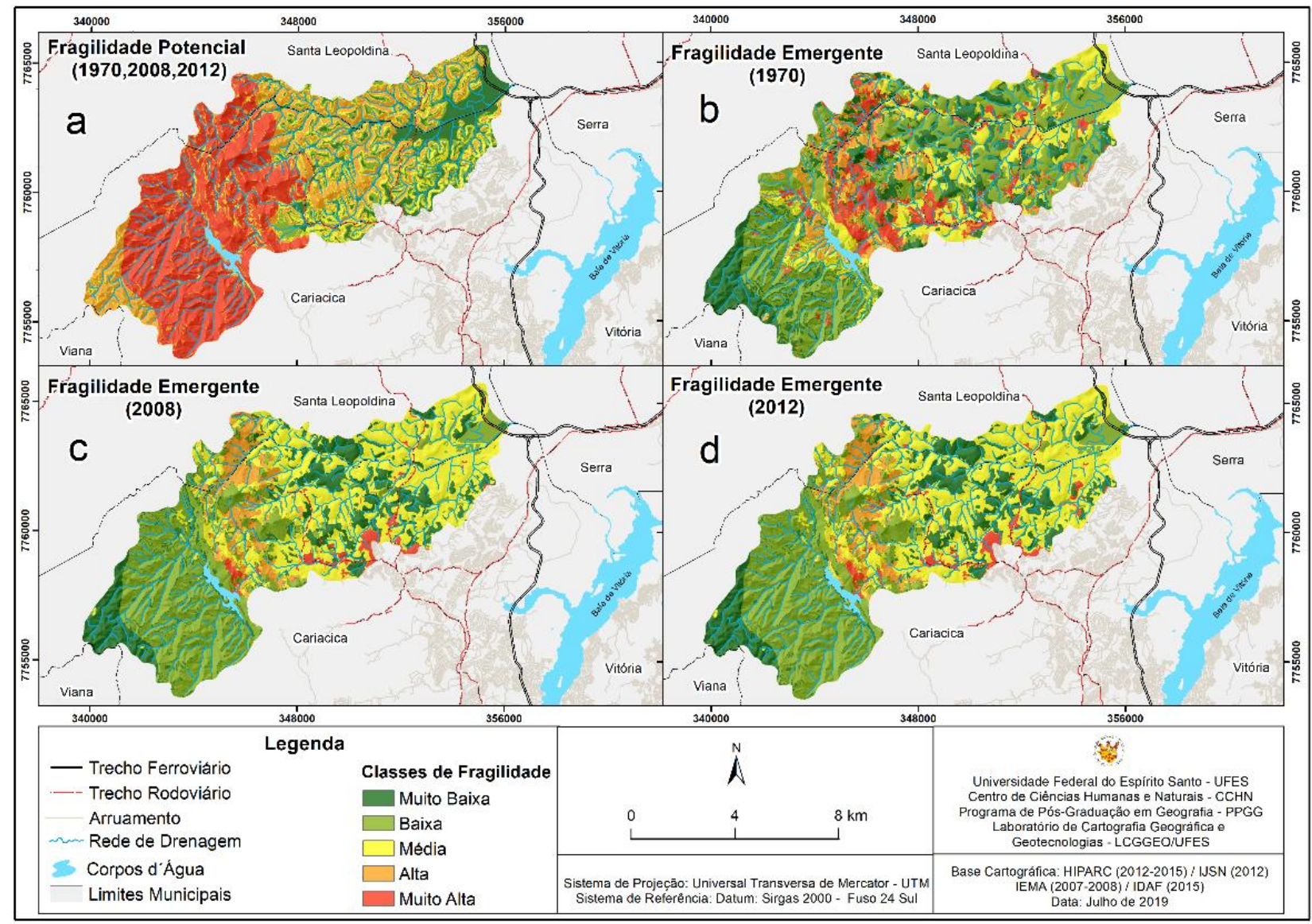

Figura 8: Mapas da Fragilidade Potencial e Emergente da bacia hidrográfica do rio Duas Bocas (ES).

Nas porções central e inferior da bacia quanto a $\mathrm{F}_{\mathrm{AE}}$, as classes de fragilidade mostraram-se bastante diversificadas, onde as classes média, alta e muito alta (porção central) tiveram maior expressividade devido as declividades acentuadas, forte dissecação do relevo, Cambissolo Háplico e Neossolo Litólico e ao incremento do cultivo agrícola de banana, que tem a capacidade de reter água, tornando o terreno frágil e com maior probabilidade da ocorrência de movimentos de massa. Na porção inferior que compreende ao baixo curso do rio Duas Bocas, encontram-se as menores declividades, tendo como classes de solos os Latossolos Vermelho-Amarelos (associados aos Argissolos) e Gleissolos, em relevo suave ondulado e plano. Desse modo, mesmo com essas características apresentadas, as classes de $\mathrm{F}_{\mathrm{AE}}$ foram média e alta, tendo em vista que a classe de uso da terra predominante é pastagem, no entanto, alguns setores apresentaram $\mathrm{F}_{\mathrm{AE}}$ muita baixa devido a regeneração de mata nativa presente nos topos de morro e fundos de vale (APP), em substituição a vegetação de macega.

\section{Conclusões}

Este artigo propôs realizar uma análise da Fragilidade Ambiental Potencial $\left(\mathrm{F}_{\mathrm{AP}}\right)$ e Fragilidade Ambiental Emergente $\left(\mathrm{F}_{\mathrm{AE}}\right)$ da bacia hidrográfica do rio Duas Bocas, através da integração de elementos naturais e antrópicos que compõem a paisagem nos anos de 1970, 2008 e 2012. Com isso, visou contribuir no intuito de subsidiar um adequado planejamento, gestão e tomada de decisão da área no que concerne a minimização de impactos relacionados a processos erosivos, eventuais movimentos de massa e inundações. Desse modo, considerando somente as variáveis físicas, foi possível verificar as porções de bacia com as mais altas e mais 
baixas classe de $\mathrm{F}_{\mathrm{AP}}$, e com a adição da variável uso e cobertura da terra, pode-se detectar os segmentos que foram atenuados na $\mathrm{F}_{\mathrm{AE}}$. Desse modo, mesmo diante de relevo fortemente dissecado, com declividades acentuadas e solos suscetíveis a erosão, o uso e cobertura da terra funcionou como um fator positivo na amenização de impactos socioambientais.

Diante desse contexto, constatou-se que a metodologia adotada apresentou resultados satisfatórios e atendeu aos objetivos propostos. Valendo ressaltar que trata-se de uma metodologia bastante consolidada, que fora aplicada exaustivamente em outras bacias hidrográficas para determinar a fragilidade ambiental potencial e emergente. Contudo, mesmo com sua eficácia em termos de aplicabilidade, adaptações em seus parâmetros, quanto as variáveis utilizadas, podem ser realizadas com a finalidade de creditar uma maior confiabilidade as caraterísticas de uma dada bacia hidrográfica estudada.

\section{Agradecimentos}

Os autores agradecem à Coordenação de Aperfeiçoamento de Pessoal de Nível Superior - CAPES e à Fundação de Amparo à Pesquisa e Inovação do Espírito Santo - FAPES pela concessão de bolsa de mestrado. Assim como o apoio financeiro da Pró-Reitoria de Extensão - PROEX/UFES pela concessão da bolsa de extensão ao Laboratório de Monitoramento e Modelagem de Sistemas Ambientais LAMOSA/UFES.

\section{Referências}

AMARAL, R; ROSS, J. L. S. As Unidades Ecodinâmicas na Análise da Fragilidade Ambiental do Parque Estadual do Morro do Diabo e Entorno, Teodoro Sampaio/SP. GEOUSP - Espaço e Tempo, n. 26, São Paulo, 2009.

AMORIM, R. C. F; RIBEIRO, A; LEITE, C.C; LEAL, B.G; SILVA, J.B.G. Avaliação do Desempenho de dois Métodos de Espacialização da Precipitação Pluvial para o Estado de Alagoas. Acta Scientiarum Technology, v. 30, n. 1, 2008. p.87-91.

BASTOS, K. V et al. Ritmo Pluviométrico da Bacia do Rio Duas Bocas (ES). I Simpósio Internacional de Águas, Solos e Geotecnologias - SASGEO, Uberaba-MG, 2015.

BERTRAND, G. Paisagem e Geografia Física Global: Esboço Metodológico. In: BERTRAN, G; BERTRAND, C (Orgs). Uma Geografia Transversal e de Travessias: o meio ambientes através dos territórios e das temporalidades. Organizador: Messias Modesto do Passos. Maringá: Ed. Massoni, 2007.

BOJÓRQUEZ-TAPIA, L. A; CRUZ-BELLO, G. M; LUNA-GONZÁLEZ, L. Connotative land degradation mapping: a knowledge-based approach to land degradation assessment. Environmental Modelling \& Software 2013; 40: 51-64. http://dx.doi. org/10.1016/j.envsoft.2012.07.009, 2013.

CARMO, J. P. A; SOUZA, G. F; POLIDERO, M; LOLLO, J. A. Análise da Fragilidade Ambiental em Áreas Urbanas. O caso do município de Londrina - PR. Anais XV Simpósio Brasileiro de Sensoriamento Remoto - SBSR. INPE. Curitiba, 2011. p.0855.

CASTRO, W. J.; LEMKE-DE-CASTRO, M. L.; OLIVEIRA LIMA, J.; OLIVEIRA, L. F. C. RODRIGUES, C.; FIGUEIREDO, C. C. Erodibilidade de solos do Cerrado Goiano. Revista Agronegócios e Meio Ambiente, v. 4, n. 2, p.305-320, 2011.

CHILDS, C. Interpolating Surfaces In: ArcGIS Spatial Analyst. ArcUse, 2004.

CPRM-COMPANHIA DE PESQUISA E RECURSOS MINERAIS. Geologia e recursos minerais da folha Nova Venécia SE.24-Y-B-IV, estado do Espírito Santo, escala 1:100.000. Organizadores: QUEIROGA, G. N et al. Belo Horizonte: CPRM, 2012.

CRUZ, L. M; JÚNIOR, J. F. P; RODRIGUES, S. C. Abordagem Cartográfica da Fragilidade Ambiental na Bacia Hidrográfica do Glória - MG. Revista Brasileira de Cartografia no 62/03, (ISSN 0560-4613), 2010. 
CUNHA, E. R.; BACANI, V. M. Caracterização da fragilidade ambiental da bacia hidrográfica do córrego Come Onça, Água Clara - MS. Acta Geográfica, v. 10, n. 22, p.193-205, DOI: http://dx.doi.org/10.5654/acta.v10i22.2456, 2016.

CUNHA, S. B da. Morfologia dos Canais Urbanos. In: POLETO, C (Org.). Ambiente e Sedimento. ABRH. Porto Alegre, 2008, Cap.9, 404p.

EMPRESA BRASILEIRA DE PESQUISA AGROPECUÁRIA - EMBRAPA. Sistema Brasileiro de classificação de solos. Humberto Gonçalves dos Santos et al. 3 ed. rev. ampl. Brasília, 2013. 353p.

ESRI - Environmental Systems Research Institute, Inc., 2016, User Manual - Help Online, version 10.5. Disponível em: http://www.esri.com Acesso em: 20 de Julho de 2019.

GOUVEIA, I. C.M.C; ROSS, J. L. S. Fragilidade Ambiental: uma Proposta de Aplicação de Geomorphons para a Variável Relevo. Revista do Departamento de Geografia, 37 São Paulo, 123-136, 2019. https://doi.org/10.11606/rdg.v37i0.151030.

GOVERNO DO ESTADO DO ESPIRITO SANTO. Lei $\mathbf{n}^{\mathbf{0}} \mathbf{2 . 0 9 5}$, de 12 de Janeiro de 1965, 2020. Disponível em: http://servicos.iema.es.gov.br/legislacao/FileHandler.ashx?id=267\&type=2.

GOVERNO DO ESTADO DO ESPIRITO SANTO. Lei $\mathbf{n}^{\mathbf{0}}$ 4.503, de 02 de Janeiro de 1991, 2020. Disponível em: http://www3.al.es.gov.br/Arquivo/Documents/legislacao/html/LEI45031991.html

IJSN- INSTITUTO JONES DOS SANTOS NEVES. Mapeamento Geomorfológico do Estado do Espírito Santo. 19 f. Nota Técnica 28 Vitória, ES, 2012.

JAIN, S. K; GOEL, M.K. Assessing the vulnerability to soil erosion of the Ukai Dam catchments using remote sensing and GIS. Hydrological Sciences Journal; 47(1): 31-40. http://dx.doi.org/10.1080/02626660209492905, 2002.

JÚNIOR; J. L. S; OLIVEIRA, J. H. M. Caracterização da Vulnerabilidade à Erosão dos Solos da bacia do rio Juliana: APA do Pratigi-BA. Anais XVII Simpósio Brasileiro de Sensoriamento Remoto - SBSR, INPE, João Pessoa-PB, 25 a 29 de abril de 2015.

KAPPES, M.S; PAPATHOMA-KÖHLE, M; KEILER, M. Assessing physical vulnerability for multihazards using an indicator-based methodology. Applied Geography (Sevenoaks, England); 32(2): 577-590. http://dx.doi.org/10.1016/j. apgeog.2011.07.002, 2012.

KAWAKUBO, F. S; MORATO, R.G; CAMPOS, K.C; LUCHIARI, A; ROSS, J.L.S. Caracterização empírica da fragilidade ambiental utilizando geoprocessamento. In: Anais XII Simpósio Brasileiro de Sensoriamento Remoto; 2005; São José dos Campos. Goiânia: INPE; 2005. p. 2203-2210.

MARCHIORO, E; BARROSO, G. F. Avaliação de Sólidos Transportados, Parâmetros da Morfometria e Solos de Seções Fluviais do Córrego Naiá-assú (Reserva Biológica de Duas Bocas/ES. Caderno de Pesquisa (PPGE/UFES), Espírito Santo, V. 01, N.01, 1996, p. 185-195.

MARTÍN-DUQUE, J. F; GARCÍA, JC; URQUÍ, LC. Geoheritage information for geoconservation and geotourism through the categorization of landforms in a Karstic Landscape: a case study from Covalagua and Las Tuerces (Palencia, Spain). Geoheritage; 4(1-2): 93-108. http://dx.doi. org/10.1007/s12371-012-0056-2, 2012.

MARTINS, R.N; COLARES, A.P.F; ALMEIDA, S.L.H; ZANELLA, M.A; NERY, C.V.M. Fragilidade potencial e emergente na bacia do rio Peruaçu, região norte de Minas Gerais. Revista Brasileira de Geomática, Curitiba, v. 6, n. 2, p. 99-118, abr/jun. 2018.

MAXIMIANO, L. A. Considerações sobre o conceito de paisagem. Revista RA'E GA, Curitiba, n. 8, p. 8391, 2004. 
MESSIAS, C. G.; FERREIRA, M. F. M.; RIBEIRO, M. B. P.; MENEZES, M. D. Análise empírica de fragilidade ambiental utilizando técnicas de geoprocessamento: o caso da área de influência da hidrelétrica do Funil - MG. Revista Geonorte, v. 2, n. 4, p. 112-125, 2012.

NETO, M. C. P.; FERNANDES, E. Fragilidade ambiental da bacia hidrográfica do rio Seridó (RN/PB Brasil). Revista Brasileira de Geomorfologia, v. 16, n. 3, p. 399-411, 2015. http://dx.doi.org/10.20502/rbg.v16i3.603.

PERRONE, A. Estudos Preliminares sobre a Carga de Sólidos Transportados, Parâmetros Morfométricos e Pluviométricos da Bacia do Córrego Pau Amarelo - Reserva Biológica de Duas Bocas - ES. 1995, 55 f. Monografia (Graduação) - Universidade Federal do Espírito Santo, Vitória, 1995.

RADAMBRASIL. Projeto Radam Brasil. Folhas 23/24 Rio de Janeiro/Vitória.V. 32, Rio de Janeiro, 1983. RATCLIFFE, D.A. Criteria for the selection of nature reserves. Advancement of Sciences, 27: 294-296, 1971.

ROCHA, A. S.; CUNHA, J. E.; MARTINS, V. M. Mapeamento das fragilidades potencial e emergente da Bacia Hidrográfica do Córrego Guavirá, Marechal Cândido Rondon - Paraná. Revista Perspectiva Geográfica, v. 8, n. 9, p.1-21, 2013.

RODRIGUEZ, J. M. M; SILVA, E. V; CAVALCANTI, A. P. B. Geoecologia das Paisagens: Uma Visão Geossistêmica da Análise Ambiental. Ed. $2^{\text {a }}$ Editora: UFC, Fortaleza, 2007.

ROSS, J. L. S. Análise empírica da fragilidade dos ambientes naturais e antropizados. Revista do Departamento de Geografia, v. 8, n. 1, p. 3-12, 1994. http://dx.doi.org/10.7154/RDG.1994.0008.0006.

ROSS, J. L. S. Ecogeografia do Brasil: Subsídios para planejamento ambiental. São Paulo: Editora Oficina de Textos, 2006.

ROSS, J.L.S. Landforms and environmental planning: Potentialities and Fragilities. Revista do Departamento de Geografia. 38-51, 2012.

SALGUEIRO, T.B. Paisagem e Geografia. Finisterra, Lisboa, XXXVI, 72, P. 37-53, 2001.

SANTOS, C. A; SOBREIRA, F. G. Análise da Fragilidade e Vulnerabilidade Natural dos Terrenos aos Processos Erosivos como base para o Ordenamento Territorial: o caso das bacias do Córrego Carioca, Córrego do Bação e Ribeirão Carioca na Região do Alto Rio das Velhas-MG. Revista Brasileira de Geomorfologia, Ano 9, n. 12008.

SANTOS, C. N. C. de. Entre o litoral Sul de Sergipe e o litoral Norte da Bahia: onde as políticas territoriais se encontram. 2017. 292f. Tese (Doutorado em Geografia) Programa de pós-Graduação em Geografia, Universidade Federal de Sergipe. São Cristóvão, 2017.

SANTOS, J.R.U; MARCHIORO, E. Fragilidade Emergente da Bacia Hidrográfica do Rio Duas Bocas, Espírito Santo: uma análise integradora da paisagem. Revista GEOgrafias, v.26, n.2, (ISSN 2237-549X), 2018.

SANTOS, R. F. Planejamento Ambiental: Teoria e Prática. Ed. Oficina de Textos. São Paulo, 2004.

SCHIER, R. A. Trajetórias do conceito de paisagem na geografia. Revista RA'E GA, Curitiba, n. 7, p. 79$85,2003$.

SILVEIRA, C.T; OKA-FIORI, C. Análise Empírica da Fragilidade Potencial e Emergente da bacia do rio Cubatãozinho, Estado do Paraná. Caminhos de Geografia, Uberlândia v. 8, n. 22, set/2007 p. 1 - 17.

SILVEIRA, E. L. D. Paisagem: um conceito chave em Geografia. In: 12 $^{\circ}$ Encontro de Geógrafos da América Latina - EGAL, Montevidéo. 2009. 
SOUZA, S.O; VALE, C.C. Vulnerabilidade Ambiental da Planície Costeira de Caravelas (BA) como subsídio ao Ordenamento Ambiental. Sociedade \& Natureza, Uberlândia, 28 (1): 147-160, jan/abr/2016.

SPÖRL C.; ROSS J. L. S. Análise comparativa da fragilidade ambiental com aplicação de três modelos. GEOUSP. Espaço e Tempo, São Paulo, n. 15. p. 39-49, 2004.

TRICART, J. Ecodinâmica. Rio de Janeiro: FIBGE, Secretaria de Planejamento da Presidência da República, 1977.97p.

VALLE, I. C; FRANCELINO, M.R; PINHEIRO, H.S.K. Mapeamento da Fragilidade Ambiental na Bacia do Rio Aldeia Velha, RJ. Floresta e Ambiente. 23(2): 295-308, ISSN 2179-8087 (online), 2016. http://dx.doi.org/10.1590/2179-8087.107714. 